\title{
A Study on the outcome of surgical management of Unstable Intertrochanteric Fractures in the geriatric population by various modalities
}

\author{
V Ramreddy ${ }^{1}$, Mohd Inayatulla Khan ${ }^{2}$
}

${ }^{1}$ Associate Professor, Department of Orthopedics, Prathima Institute of Medical Sciences, Naganur, Karimnagar, Telangana State. ${ }^{2}$ Assistant Professor, Department of Physiology, Rajiv Gandhi Institute of Medical Sciences [RIMS], Adilabad. Telangana State. Address for communication: Dr. V Ramreddy. Associate Professor, Department of Orthopedics, Prathima Institute of Medical Sciences, Naganur, Karimnagar, Telangana State. Email: orthoramreddy@gmail.com

Dr. Mohd Inayatulla Khan, H.No. 5-3-5/8, Kubra Apartments, Flat No. 304, 2nd floor, Doctors Street, Karimnagar-505001. Telangana State. Email: drkhan123@rediffmail.com Mobile:09948959937

\section{ABSTRACT}

Background: Unstable hip fractures in elderly patients a unique challenge for orthopedic surgeons. Most of the cases are to be managed by surgical intervention. The problems of old age include the presence of osteoporosis, pre-existing arthritis, the overall health of the patient. We in the present study tried to evaluate the functional outcome of surgical management of unstable intertrochanteric fractures by various methods and study the effectiveness and complications of the operative management of unstable fractures.

Methods: This cross-sectional study was carried out in the Department of Orthopedics, Prathima Institute of Medical Sciences, Nagunur, Karimnagar. All patients with unstable intertrochanteric fractures with age $>65$ years who are treated by the surgical intervention were included in the study. All the patients were operated in Spinal anesthesia and The standard surgical procedures were followed for different modalities like DHS, PFN, Enders Nail's and cemented bipolar hemiarthroplasty was done.

Results: Out of $n=50$ patients $n=28(56 \%)$ were female and $n=22(44 \%)$ were males. The average duration of hospital stay was 14 days, with a range of 10-25 days. The mean blood loss in cemented bipolar hemiarthroplasty was 300 ml, PFN 100 $\mathrm{ml}$, DHS was $250 \mathrm{ml}$, and Ender's Nail was $50 \mathrm{ml}$. In our study of Bipolar hemiarthroplasty out of $n=9$ patients $n=3(33.34 \%)$ had excellent, $n=5(55.56 \%)$ good outcome, $n=1(11.12 \%)$ had fair outcomes respectively. Out of $n=9$ patients of PFN $n=4(44.44$ $\%)$ of excellent, good $n=4(44.44 \%)$, fair $n=1(11.12 \%)$ patient and no poor results. Out of $n=25$ patients of DHS $n=20(80 \%)$ patients are excellent to good results, $n=3(12 \%)$ patient had fair and $n=2(8 \%)$ patients had poor results. Out of 7 patients of Ender's nails $n=2(28.573$ ) had excellent and $n=3(42.85 \%)$ had good and $n=1(14.28 \%)$ fair, $n=1(14.28)$ had poor results. Conclusion: Intertrochanteric Fractures in the geriatric population are a unique challenge it requires early operative management which will reduce both mortality and morbidity. Early mobilization following operative treatment will reduce the risks associated with prolonged bed rest in geriatric patients. Since failure rate is still high in unstable intertrochanteric fractures selection of proper implants is important for the ultimate success of the treatment.

Keywords: Unstable Intertrochanteric Fractures, Geriatric Population, Surgical Management

\section{INTRODUCTION}

Intertrochanteric fractures are a major cause of morbidity and mortality in the elderly population. The incidence of all hip fractures is approximately 80 per 100,000 persons. Intertrochanteric fracture makes up $45 \%$ of all hip fractures ${ }^{[1]}$. Unstable intertrochanteric fractures in elderly patients are associated with high rates of morbidity and mortality although the results have improved with the use of internal fixation ${ }^{[2]}$. In these patients, however, a combination of osteoporosis and instability often precludes the early resumption of full weight-bearing ${ }^{[3]}$. Trochanteric fractures almost invariably occur as a result of fall, involving both direct and indirect forces. Koval et al; ${ }^{[4]}$ postulated that Intertrochanteric fractures constitute almost half of all fractures of the proximal femur. Direct forces act along the axis of the femur or directly over the greater trochanter to result in Intertrochanteric fractures. Indirect forces include the pull of the iliopsoas muscle on the lesser trochanteric and pull of the abductor muscle on the greater trochanteric region. Intertrochanteric fractures like femoral neck fractures are commonly encountered in the practice of Orthopedic Surgery. Intertrochanteric fractures usually occur in patients over 60 years of age commonly and are three times more frequent in women than men because women tend to be less active and develop postmenopausal osteoporosis. Severe osteoporosis in this age group is responsible for the high incidence of trochanteric fractures with minimal to moderate trauma. Norton and Ruska described patients with Intertrochanteric fractures to be 10 to 12 years older than patients with intracapsular femoral neck fractures, the average age reported in these patients 60 to 75 years ${ }^{[5]}$. Intertrochanteric fractures 
frequently occur through bone affected by osteoporosis, the degree of osteoporosis can be determined by Singh's index, this index classifies the severity of osteoporosis by the radiographic evaluation of trabecular pattern 6 of the proximal femur ${ }^{[6]}$. Surgery in trochanteric fractures is important in elderly patients for the prevention of complications associated with conservative treatment like pressure sores, pulmonary infection, atelectasis, melanin, etc, and aimed at early rehabilitation and mobilization.

Internal fixation does provide immediate fracture fixation but in elderly patients with osteoporotic bones, complications like loosening, implant penetration, loss of fixation, cut through of implant are not uncommon, this is the emerging role of cemented bipolar in the management of intertrochanteric fractures. The present study consists of 50 cases of unstable intertrochanteric fractures treated by different modalities like DHS, PFN, Enders Nail's and cemented bipolar hemiarthroplasty.

\section{Material and methods}

This cross-sectional study was carried out in the Department of Orthopedics, Prathima Institute of Medical Sciences, Nagunur, Karimnagar. Institutional Ethical committee permission was obtained for the study. Written consent was obtained from all the participants of the study. A total of $n=50$ elderly patients with unstable intertrochanteric fractures of femur who are treated with DHS and PFN, Ender's nails and Cemented bipolar prosthesis were included in the study. Inclusion criteria: All patients with unstable intertrochanteric fractures with age $>65$ years

Exclusion Criteria were Intertrochanteric fractures in patient's age $<65$. An elderly patient with unstable Intertrochanteric fractures those having other medical problems which make them bedridden or unfit for anesthesia. After the patient with unstable intertrochanteric fracturewas admitted to the hospital all the necessary clinical details were recorded in proforma prepared for this study. Radiological evaluation was done and admitted to the ward after necessary resuscitation and splintage with skeletal traction. The following Investigations were done routinely on all these patients preoperatively. Blood $\mathrm{Hb} \%$, Bleeding time, Clotting time, Blood grouping and Crossmatching, Fasting and Postprandial blood sugar, Blood urea and Serum Creatinine, Urine Albumin, Sugar, Microscopic examination. X-ray Pelvis with both hips (AP view), Chest X-ray PA view in necessary patients All the patients were evaluated for associated medical problems and were referred to the respective department and treated accordingly. Associated injuries were evaluated and treated simultaneously. The patients were operated on an elective basis after overcoming the avoidable anesthetic risks. Pre - Operative Planning included AP-X Rays of involved Hip and traction views were taken and Singh's index assessed, age of the patient and fracture classification considered in the selection of the treatment modality Geriatric patients (> 65years) with unstable fracture and Singh's index $<4$ cemented bipolar Unstable fractures with subtrochanteric extension and reverse oblique types - proximal femoral nail All remaining cases - dynamic hip screw and ender's nails. All the patients were operated in Spinal anesthesia and The standard surgical procedures were followed for different modalities like DHS, PFN, Enders Nail's and cemented bipolar hemiarthroplasty was done. Intraoperative parameters were recorded and the total duration of surgery was also noted. Postoperatively the patients operated for DHS were made to walk on non-weight bearing with support from 5 th to 7 th postoperative day. At 6 weeks postoperative period toe-touch weight-bearing was initiated. After clinical and radiological signs of the union, they were allowed full weightbearing. Patients operated with $\mathrm{BH}$ were made to stand with the support of a walker and allowed to walk with full weightbearing by 4 th or 5 th postoperative day. Patients operated with PFN were made to stand by 3rd or 4th postoperative day and made to walk full weight bearing with support of a walker. Postoperative complications were treated if present. The patients were followed up every month for the first three months and then every three months for the first year and every six-monthly from then onwards.

Results

Age incidence the average age of patients in our series was above 65 years. Out of $n=50$ patients $n=28(56 \%)$ were female and $n=22(44 \%)$ were males. The Female predominance was possibly due to postmenopausal osteoporosis and decrease activity as compared to males of the same age group. Details are shown in table 1.

Table 1: showing the age-wise and sex-wise distribution of patients in the study

\begin{tabular}{|c|c|c|c|c|}
\hline $\begin{array}{c}\text { Age } \\
\text { group }\end{array}$ & Male & Female & $\begin{array}{c}\text { No. of } \\
\text { patients }\end{array}$ & Percentage \\
\hline $65-75$ & 11 & 14 & 25 & 50 \\
\hline $75-85$ & 8 & 10 & 18 & 36 \\
\hline $85-95$ & 3 & 4 & 7 & 14 \\
\hline Total & 22 & 28 & 50 & 100 \\
\hline
\end{tabular}

Graph 1: Showing the side involved in the fractures

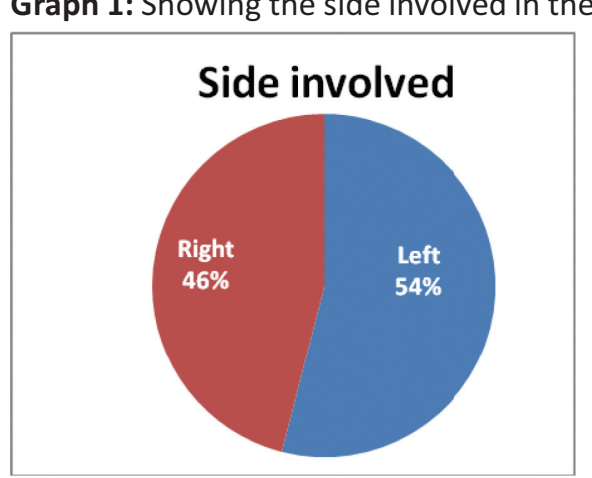


In this study commonest mode of unstable intertrochanteric injury was due to a trivial fall, while walking inside and outside the house. This is probably due to severe osteoporosis in the elderly, decreased vision in the elderly and lack of coordination and reaction time. In our study, the unstable intertrochanteric fracture was common due to fall on a slippery surface Table 2.

Table 2: Mechanism of the injury in cases of unstable intertrochanteric fractures

\begin{tabular}{|l|c|c|}
\hline \multicolumn{1}{|c|}{ Mode of Injury } & No. of Patients & Percentage \\
\hline Fall on Slippery Floor & 30 & $60 \%$ \\
\hline Fall From Stairs \& Height & 10 & $20 \%$ \\
\hline RTA & 7 & $14 \%$ \\
\hline Miscellaneous & 3 & $6 \%$ \\
\hline
\end{tabular}

The average duration of hospital stay was 14 days, with a range of 10-25 days. The mean blood loss in cemented bipolar hemiarthroplasty was 300 ml, PFN 100 ml, DHS was 250ml, and Ender's Nail was $50 \mathrm{ml}$.

Table 3: Surgical Procedure Employed for the treatment of unstable intertrochanteric fractures

\begin{tabular}{|l|c|c|}
\hline \multicolumn{1}{|c|}{ Surgical Procedure } & No. of Patients & Percentage \\
\hline Dynamic Hip Screw & 25 & $50 \%$ \\
\hline Proximal Femoral Nail & 9 & $18 \%$ \\
\hline Cemented Bipolar & 9 & $18 \%$ \\
\hline Enders Nail & 7 & $14 \%$ \\
\hline
\end{tabular}

In our study of Bipolar hemiarthroplasty out of $n=9$ patients $n=3(33.34 \%)$ had excellent, $n=5(55.56 \%)$ good outcome, $n=1(11.12 \%)$ had fair outcomes respectively. Out of $n=9$ patients of PFN $n=4$ (44.44\%) of excellent, good $n=4(44.44 \%)$, fair $n=1(11.12 \%)$ patient and no poor results. Out of $n=25$ patients of DHS $n=20$ (80\%) patients are excellent to good results, $n=3(12 \%)$ patient had fair and $n=2(8 \%)$ patients had poor results. Out of 7 patients of Ender's nails $n=2(28.573)$ had excellent and $n=3(42.85 \%)$ had good and $n=1(14.28 \%)$ fair, $\mathrm{n}=1(14.28)$ had poor results (table 4$)$.

Table 4: Outcome of various treatments in the study

\begin{tabular}{|c|c|c|c|c|}
\hline Outcome & $\begin{array}{c}\text { Cemented bipolar } \\
\text { hemiarthroplasty }\end{array}$ & PFN & DHS & $\begin{array}{c}\text { Enders } \\
\text { Nail }\end{array}$ \\
\hline
\end{tabular}

\begin{tabular}{|l|c|c|c|c|c|c|c|c|}
\hline & $\begin{array}{c}\text { No. of } \\
\text { Patients }\end{array}$ & $\%$ & $\begin{array}{c}\text { No. of } \\
\text { Patients }\end{array}$ & $\%$ & $\begin{array}{c}\text { No. of } \\
\text { Patients }\end{array}$ & $\%$ & $\begin{array}{c}\text { No. of } \\
\text { Patients }\end{array}$ & $\%$ \\
\hline Excellent & 11 & 33.34 & 4 & 44.45 & 8 & 32 & 2 & 28.57 \\
\hline Good & 8 & 55.56 & 4 & 44.45 & 12 & 48 & 3 & 42.85 \\
\hline Fair & 3 & 11.12 & 1 & 11.12 & 3 & 12 & 1 & 14.28 \\
\hline Poor & 22 & 0 & 0 & 0 & 2 & 8 & 1 & 14.28 \\
\hline
\end{tabular}

In the DHS group varus malunion, screw back out and implant failure was seen in $n=1(4 \%)$ case each of total $n=25$ cases treated with DHS. Superficial infection was and screw back out was seen in $n=1(11.12 \%)$ of total $n=9$ cases treated with PFN. Superficial infection and limb lengthening were found in $n=1(11.12 \%)$ of total $n=9$ cases. In Ender's Nail group out of $n=7$ cases, $n=2$ cases were found with distal migration of nails and knee joint stiffness was in $n=3$ and $n=1$ each had limb shortening and External rotational malalignment.

Table 5: Postoperative Complications in Dynamic Hip Screw Group

\begin{tabular}{|l|c|c|}
\hline \multicolumn{1}{|c|}{ Complications } & No. of Patients & Percentage \\
\hline Loss of Reduction & 0 & 0 \\
\hline Screw Cut Out & 0 & 0 \\
\hline Varus Malunion & 1 & $4 \%$ \\
\hline Screw Back Out & 1 & $4 \%$ \\
\hline Non-Union & 0 & 0 \\
\hline Implant Failure & 1 & $4 \%$ \\
\hline
\end{tabular}

Table 6: Postoperative Complications in Proximal Femoral Nail Group

\begin{tabular}{|l|c|c|}
\hline \multicolumn{1}{|c|}{ Complications } & No. of Patients & Percentage \\
\hline Implant Failure & 0 & 0 \\
\hline Superficial infection & 1 & $11.12 \%$ \\
\hline Screw Back Out & 1 & $11.12 \%$ \\
\hline Thigh Pain & 0 & 0 \\
\hline Non-Union & 0 & 0 \\
\hline Peri Prosthetic \# & 0 & 0 \\
\hline
\end{tabular}

Table 7: Postoperative Complications in Cemented Bipolar Group

\begin{tabular}{|l|c|c|}
\hline \multicolumn{1}{|c|}{ Complications } & No. of Patients & Percentage \\
\hline Dislocation & 0 & 0 \\
\hline Superficial infection & 1 & $11.12 \%$ \\
\hline Limb Shortening & 1 & $11.12 \%$ \\
\hline Limb Lengthening & 0 & 0 \\
\hline Peri Prosthetic fracture & 0 & 0 \\
\hline Aseptic Loosening & 0 & 0 \\
\hline
\end{tabular}


Table 8: Post Operative Complications in Ender's Nail Group

\begin{tabular}{|l|c|c|}
\hline \multicolumn{1}{|c|}{ Complications } & No. of Patients & Percentage \\
\hline Distal Migration of Nails & 2 & 28.5 \\
\hline Supra Condylar Fracture & 0 & 0 \\
\hline Infection & 0 & 0 \\
\hline Proximal migration of Nails & 0 & 0 \\
\hline Shortening & 1 & 14.2 \\
\hline Knee joint stiffness & 3 & 42.8 \\
\hline $\begin{array}{l}\text { External Rotational } \\
\text { Malalignment }\end{array}$ & 1 & 14.2 \\
\hline
\end{tabular}

\section{Discussion}

In the present study of $n=50$ patients of intertrochanteric fractures, $n=9$ cases were treated with PFN, $\mathrm{n}=25$ cases with DHS, $\mathrm{n}=9$ cases with bipolar Hemiarthroplasty and $n=7$ with Ender's nails. The data was assessed; analyzed, evaluated it was observed that the male to female ratio was 44:56. The sex incidence in our series is almost similar to the reported series. In our study, the Intertrochanteric fractures common in elderly female due to hormonal imbalance in postmenopausal age and associated osteoporosis is due to poor hormonal replacement therapy and malnutrition in our country. $\mathrm{N}=23$ (46\%) patients had fracture on right side and $\mathrm{n}=27$ (54\%) patients had fracture on left side. But no specific reasons can be given for the more frequent involvement of the left hip. In our study we found $88 \%$ had good and excellent results with bipolar hemiarthroplasty comparable to other studies conducted by Rosenfeld et al; ${ }^{[7]}$ used arthroplasty and reported $86 \%$ satisfactory results in the early period. Rodop et ${ }^{a l} ;{ }^{[8]}$ in a study of primary bipolar hemiprosthesis for unstable intertrochanteric fractures in 37 elderly patients obtained $82 \%$ of excellent to good results after 12 months according to the Harris hip-scoring system. Haentjens P et al; ${ }^{[9]}$ compared the clinical results of internal fixation and bipolar arthroplasty for unstable trochanteric fractures and reported $75 \%$ satisfactory results and less postoperative complications in the latter group. They insisted that early weight-bearing was the major factor responsible for decreasing postoperative complications. Klinger HM et al; ${ }^{[10]}$ studying PFN and DHF in unstable per and intertrochanteric femoral fractures found no difference in functional outcome between the two groups. In the case of PFN $17.2 \%$ revisions were necessary and in the case of DHS with TBPP $21.6 \%$. A shorter operation time (43 vs. $61 \mathrm{~min}$ ) and a considerable shorter in-patient stay (20 vs. 24 days) were common with PFN. Full-weight-bearing immediately after the osteosynthesis was possible for $98 \%$ of the PFN patients and $81 \%$ of the DHS/TBPP patients. In the case of Ender's nails in our study $71.42 \%$ of good to excellent functional results. Marcos HS et al; ${ }^{[11]}$ diaphyseal fractures were treated with intramedullary nails or Ender pins. During 1 year of follow-up, the fractures of $90.0 \%$ of the patients with intramedullary nails and $95.7 \%$ of patients with Ender pins healed within an average of 21.5 weeks and 20.9 weeks, respectively. In a study by Pajarein J et al; ${ }^{[12]}$ of $n=108$ patients of pertrochanteric fractures treated with DHS and PFN, found that PFN allowed the faster restoration of postoperative walking ability when compared with DHS. This correlated with our study where the restoration of postoperative walking ability was faster in PFN, Bipolar Hemiarthroplasty when compared with DHS and Ender's Nails. This correlated with our study where the restoration of postoperative walking ability was faster in PFN, Bipolar Hemiarthroplasty when compared with DHS and Ender's Nails.

\section{Conclusion}

Intertrochanteric Fractures in the geriatric population is a unique challenge it requires early operative management which will reduce both mortality and morbidity. Early mobilization following operative treatment will reduce the risks associated with prolonged bed rest in geriatric patients. Since failure rate is still high in unstable intertrochanteric fractures selection of proper implants is important for the ultimate success of the treatment.

\section{REFERENCES}

1. JD Zuckerman: Hip fracture. N Engl J Med 1996; 334:15191523.

2. Jensen, J. S. Trochanteric Fractures. An Epidemiological, Clinical and Biomechanical Study. Acta Orthop Scandinavica, Supplementum 1981;188: 1-100.

3. Bergman, G. D. Winquist, R. A. Mayo, K. A. and Hansen, S. $J R$. Subtrochanteric Fracture of the Femur. Fixation Using the Zickel Nail. J. Bone and Joint Surg 1987; 69-A: 103240.

4. Kova UKJ, Zuckerman LD. Hip fractures, evaluation, and treatment of intertrochanteric fracture. IAAOS. 1994;2:150-156

5. Bendo JA, Weiner LS, Strauss E, and Yang E: Collapse of intertrochanterichip fractures fixed with sliding screws. Orthop Rev Suppl 1994; 30-37.

6. Singh $M$, Nagrath $A R$, Maini PS. Changes in trabecular pattern of the upper end of the femur as an index of osteoporosis. J Bone Joint Surg Am. 1970;52(3):457-67.

7. Rosenfeld RT, Schwartz DR, Alter AH. Prosthetic replacements for trochanteric fractures of the femur. J Bone Joint Surg Am. 1973;55:420.

8. Rodop O, Kiral A, Kaplan H, Akmaz I. Primary bipolar hemiprosthesis for unstable intertrochanteric fractures. Int Orthop 2002;26:233-37. 
9. Haentjens P, Lamaraski G. Endoprosthetic replacement of unstable, comminuted intertrochanteric fracture of the femur in the elderly, osteoporotic patient: a review Disabil Rehabil 2005; 27(18-19):1167-80.

10. Klinger HM, Baums MH, Eckert $M$, Neugebauer R. A comparative study of unstable per and intertrochanteric femoral fractures treated with dynamic hip screw (DHS) and trochanteric butt-press plate vs proximal femoral nail (PFN). Zentralbl Chir 2005; 130(4):301-06.

11. Marcos Hideyo Sakaki, Alberto Tesconi Crocci, Arnaldo Valdir Zumiott. Comparative study of the locked intramedullary nail and ender pins in the treatment of tibial diaphyseal fractures. Clinics 2007;62(4):455-64.

12. Pajarinen J, Lindahl J, Michelson O, Savolainen V, Hirvensalo E. Pertrochanteric femoral fractures treated with dynamic hip screws or a proximal femoral nail: A randomized study comparing post-operative rehabilitation. J Bone Joint Surg Br. 2005;87(1):76-81.

How to cite this article : Ramreddy V , Khan MI . A Study on the outcome of surgical management of Unstable Intertrochanteric Fractures in the geriatric population by various modalities. Perspectives in Medical Research 2020; 8(1): $43-47$

Sources of Support: Nil,Conflict of interest:None declared. 